\title{
Asymptotic Properties of Solutions to Third-Order Nonlinear Neutral Differential Equations
}

\author{
Qi Li, ${ }^{1}$ Rui Wang, ${ }^{1}$ Fanwei Meng, ${ }^{2}$ and Jianxin Han $^{3}$ \\ ${ }^{1}$ Qingdao Technological University, Feixian, Shandong 273400, China \\ ${ }^{2}$ Department of Mathematics, Qufu Normal University, Qufu, Shandong 273165, China \\ ${ }^{3}$ College of Mathematics and Information Science, Xinyang Normal University, Xinyang 464000, China
}

Correspondence should be addressed to Qi Li; liqi_2006@163.com and Rui Wang; rwang_2005@163.com

Received 26 March 2014; Accepted 12 May 2014; Published 25 May 2014

Academic Editor: Tongxing Li

Copyright (C) 2014 Qi Li et al. This is an open access article distributed under the Creative Commons Attribution License, which permits unrestricted use, distribution, and reproduction in any medium, provided the original work is properly cited.

The aim of this work is to discuss asymptotic properties of a class of third-order nonlinear neutral functional differential equations. The results obtained extend and improve some related known results. Two examples are given to illustrate the main results.

\section{Introduction}

In this work, we study the asymptotic behavior of solutions of the third-order neutral differential equation

$$
\begin{aligned}
& \left(a(t)\left(b(t)(x(t)+p(t) x(\sigma(t)))^{\prime}\right)^{\prime}\right)^{\prime} \\
& \quad+q(t) f(x(\tau(t))) g\left(x^{\prime}(t)\right)=0 .
\end{aligned}
$$

We always assume that the following conditions hold:

$$
\begin{aligned}
& \left(H_{1}\right) a(t), b(t), p(t), q(t) \in C\left(\left[t_{0}, \infty\right),[0, \infty)\right), 0 \leq p(t) \leq \\
& p_{0}<1 ; \\
& \left(H_{2}\right) \sigma(t), \tau(t) \in C\left(\left[t_{0}, \infty\right),[0, \infty)\right), \sigma(t) \leq t, \tau(t) \leq t \\
& \quad \lim _{t \rightarrow \infty} \sigma(t)=\lim _{t \rightarrow \infty} \tau(t)=\infty ; \\
& \left(H_{3}\right) f \in C(R, R), f(x) / x \geq K>0 \text {, for all } x \neq 0 ; \\
& \left(H_{4}\right) g \in C(R,[L, \infty)), L>0 ; \\
& \left(H_{5}\right) \int_{t_{0}}^{\infty}(1 / a(t)) \mathrm{d} t=\int_{t_{0}}^{\infty}(1 / b(t)) \mathrm{d} t=\infty .
\end{aligned}
$$

Set $z(t)=x(t)+p(t) x(\sigma(t))$. By a solution of (1), we mean a nontrivial function $x(t) \in C\left(\left[T_{x}, \infty\right), R\right), T_{x} \geq t_{0}$, which has the properties $z(t) \in C^{1}\left(\left[T_{x}, \infty\right), R\right), b(t) z^{\prime}(t) \in$ $C^{1}\left(\left[T_{x}, \infty\right)\right)$, and $a(t)\left(b(t) z^{\prime}(t)\right)^{\prime} \in C^{1}\left(\left[T_{x}, \infty\right)\right)$ and satisfies (1) on $\left[T_{x}, \infty\right)$. We consider only those solutions $x(t)$ of (1) which satisfies $\sup \{|x(t)|: t \geq T\}>0$ for all $T \geq T_{x}$. We assume that (1) possesses such a solution. A solution of (1) is called oscillatory if it has arbitrarily large zeros on $\left[T_{x}, \infty\right)$; otherwise, it is called nonoscillatory.

Recently, great attention has been devoted to the oscillation of various classes of differential equations. See, for example, [1-19]. Hartman and Wintner [1] and Erbe et al. [3] studied the third-order differential equation

$$
x^{\prime \prime \prime}(t)+q(t) x(t)=0 .
$$

Paper [5] studied the oscillation of third-order trinomial delay differential equation

$$
x^{\prime \prime \prime}(t)+p(t) x^{\prime}(t)+g(t) x(\tau(t))=0 .
$$

Li et al. [7] discussed (1) with $f(x(\tau(t)))=x(\tau(t))$ and $g\left(x^{\prime}(t)\right)=1$. Han [8] examined the oscillation of (1) with $b(t)=1$.

In this work, we establish some oscillation criteria for (1) which extend and improve the results in $[7,8]$.

\section{Main Results}

In the following, all functional inequalities considered are assumed to hold eventually for all $t$ large enough. Without loss of generality, we deal only with the positive solutions of (1). 
Theorem 1. Suppose that

$$
\int_{t_{0}}^{\infty} \frac{1}{b(v)} \int_{v}^{\infty} \frac{1}{a(u)} \int_{u}^{\infty} q(s) \mathrm{d} s \mathrm{~d} u \mathrm{~d} v=\infty
$$

If for some function $\rho \in C^{1}\left(\left[t_{0}, \infty\right),(0, \infty)\right)$, for all sufficiently large $t_{2}>t_{1}>t_{0}$, one has

$$
\limsup _{t \rightarrow \infty} \int_{t_{2}}^{t}\left[\rho(s) Q(s)-\frac{\left(\rho^{\prime}(s)\right)^{2} a(s)}{4 \rho(s)}\right] \mathrm{d} s=\infty,
$$

where

$$
Q(t)=\frac{K L\left(1-p_{0}\right) \int_{t_{2}}^{\tau(t)} \int_{t_{1}}^{v}(1 /(a(u) / b(v))) \mathrm{d} u \mathrm{~d} v}{\int_{t_{1}}^{t}(1 / b(u)) \mathrm{d} u}
$$

then all solutions of (1) are oscillatory or convergent to zero asymptotically.

Proof. Assume that $x$ is a positive solution of (1). Based on condition $\left(H_{5}\right)$, there are two possible cases:

$(1) z(t)>0, z^{\prime}(t)>0,\left(b(t) z^{\prime}(t)\right)^{\prime}>0$, $\left[a(t)\left(b(t) z^{\prime}(t)\right)^{\prime}\right]^{\prime}<0$

(2) $z(t)>0, z^{\prime}(t)<0,\left(b(t) z^{\prime}(t)\right)^{\prime}>0$, $\left[a(t)\left(b(t) z^{\prime}(t)\right)^{\prime}\right]^{\prime}<0$.

First, consider that $z(t)$ satisfies (1). We have

$$
x(t)=z(t)-p(t) x(\sigma(t)) \geq\left(1-p_{0}\right) z(t) .
$$

From $(1),\left(H_{3}\right)$, and $\left(H_{4}\right)$, we get

$$
\left[a(t)\left(b(t) z^{\prime}(t)\right)^{\prime}\right]^{\prime} \leq-K L\left(1-p_{0}\right) q(t) z(\tau(t)) \leq 0 .
$$

Define a function $\omega$ by

$$
\omega(t)=\rho(t) \frac{a(t)\left(b(t) z^{\prime}(t)\right)^{\prime}}{b(t) z^{\prime}(t)}, \quad t \geq t_{1}
$$

we obtain $\omega(t)>0$. Then

$$
\omega^{\prime}(t)
$$

$$
\begin{aligned}
= & \rho^{\prime}(t) \frac{a(t)\left(b(t) z^{\prime}(t)\right)^{\prime}}{b(t) z^{\prime}(t)}+\rho(t) \frac{\left(a(t)\left(b(t) z^{\prime}(t)\right)^{\prime}\right)^{\prime}}{b(t) z^{\prime}(t)} \\
& -\rho(t) \frac{a(t)\left[\left(b(t) z^{\prime}(t)\right)^{\prime}\right]^{2}}{\left(b(t) z^{\prime}(t)\right)^{2}} \\
= & \rho(t) \frac{\left(a(t)\left(b(t) z^{\prime}(t)\right)^{\prime}\right)^{\prime}}{b(t) z^{\prime}(t)} \\
& +\frac{\rho^{\prime}(t)}{\rho(t)} \omega(t)-\frac{\omega^{2}(t)}{\rho(t) a(t)} \\
\leq & -\frac{K L\left(1-p_{0}\right) \rho(t) q(t) z(\tau(t))}{b(t) z^{\prime}(t)} \\
& +\frac{\rho^{\prime}(t)}{\rho(t)} \omega(t)-\frac{\omega^{2}(t)}{\rho(t) a(t)} \\
\leq & -\frac{K L\left(1-p_{0}\right) \rho(t) q(t) z(\tau(t))}{b(t) z^{\prime}(t)} \\
& -\left[\frac{\omega(t)}{\sqrt{\rho(t) a(t)}}-\frac{1}{2} \sqrt{\frac{a(t)}{\rho(t)}} \rho^{\prime}(t)\right]^{2}
\end{aligned}
$$

By the proof of [7, Theorem 2.1], we have

$$
\omega^{\prime}(t) \leq-\left[\rho(t) Q(t)-\frac{\left(\rho^{\prime}(t)\right)^{2} a(t)}{4 \rho(t)}\right],
$$

where $Q(t)$ is defined as in (6). We obtain

$$
\int_{t_{1}}^{t}\left[\rho(s) Q(s)-\frac{\left(\rho^{\prime}(s)\right)^{2} a(s)}{4 \rho(s)}\right] \mathrm{d} s \leq-\int_{t_{1}}^{t} \omega^{\prime}(s) \mathrm{d} s .
$$

That is,

$$
\begin{array}{r}
\int_{t_{1}}^{t}\left[\rho(s) Q(s)-\frac{\left(\rho^{\prime}(s)\right)^{2} a(s)}{4 \rho(s)}\right] \mathrm{d} s \\
\quad \leq \omega\left(t_{1}\right)-\omega(t)<\omega\left(t_{1}\right)<\infty,
\end{array}
$$

which contradicts (5). Assume that case (2) holds. Using the similar proof of $\left[8\right.$, Lemma 4], we can get $\lim _{t \rightarrow \infty} x(t)=0$. This completes the proof.

Based on Theorem 1, we present a Kamenev-type criterion for (1). 
Theorem 2. Assume that (4) holds. If for some function $\rho \in$ $C^{1}\left(\left[t_{0}, \infty\right),(0, \infty)\right)$, for all sufficiently large $t_{1}>t_{0}$, one has

$$
\limsup _{t \rightarrow \infty} \frac{1}{t^{n}} \int_{t_{1}}^{t}(t-s)^{n}\left[\rho(s) Q(s)-\frac{\left(\rho^{\prime}(s)\right)^{2} a(s)}{4 \rho(s)}\right] \mathrm{d} s=\infty,
$$

then all solutions of (1) are oscillatory or convergent to zero asymptotically.

Proof. Assume that $x(t)$ is a positive solution of (1). Then by the proof of Theorem 1, we have cases (1) and (2). Let case (1) hold. Proceeding as in the proof of Theorem 1, we have (11). Then we have

$$
\begin{aligned}
\int_{t_{1}}^{t}(t & -s)^{n}\left[\rho(s) Q(s)-\frac{\left(\rho^{\prime}(s)\right)^{2} a(s)}{4 \rho(s)}\right] \mathrm{d} s \\
& \leq-\int_{t_{1}}^{t}(t-s)^{n} \omega^{\prime}(s) \mathrm{d} s .
\end{aligned}
$$

That is,

$$
\begin{aligned}
& \frac{1}{t^{n}} \int_{t_{1}}^{t}(t-s)^{n}\left[\rho(s) Q(s)-\frac{\left(\rho^{\prime}(s)\right)^{2} a(s)}{4 \rho(s)}\right] \mathrm{d} s \\
& \quad \leq-\frac{n}{t^{n}} \int_{t_{1}}^{t}(t-s)^{n-1} \omega(s) \mathrm{d} s+\left(1-\frac{t_{1}}{t}\right)^{n} \omega\left(t_{1}\right) \\
& \quad<\left(1-\frac{t_{1}}{t}\right)^{n} \omega\left(t_{1}\right)<\infty,
\end{aligned}
$$

which contradicts (14). Assume that case (2) holds. We can get $\lim _{t \rightarrow \infty} x(t)=0$. The proof is completed.

Next, we present a Philos-type criterion for (1). Let

$$
D=\left\{(t, s): t \geq s \geq t_{0}\right\}, \quad D_{0}=\left\{(t, s): t>s \geq t_{0}\right\} .
$$

We say that a function $H \in C(D, R)$ belongs to a function class $P$, if it satisfies

(i) $H(t, t)=0, t \geq t_{0} ; H(t, s)>0,(t, s) \in D_{0}$;

(ii) $H$ has a continuous and nonpositive partial derivative on $D_{0}$ with respect to the second variable, and such that

$$
-\frac{\partial H(t, s)}{\partial s}=h(t, s) \sqrt{H(t, s)}, \quad(t, s) \in D_{0} .
$$

Theorem 3. Assume that (4) holds. If for some function $\rho \in$ $C^{1}\left(\left[t_{0}, \infty\right),(0, \infty)\right)$, for all sufficiently large $t_{1}>t_{0}$, one has

$$
\limsup _{t \rightarrow \infty} \frac{1}{H\left(t, t_{1}\right)} \int_{t_{1}}^{t}\left[H(t, s) \rho(s) Q(s)-\frac{h_{1}^{2}(t, s)}{4 B(s)}\right] \mathrm{d} s=\infty,
$$

where $Q(t)$ is defined as in (6), $B(t)=1 / \rho(t) a(t)$, and

$$
h_{1}(t, s)=h(t, s)-\frac{\rho^{\prime}(s)}{\rho(s)} \sqrt{H(t, s)},
$$

then all solutions of (1) are oscillatory or convergent to zero asymptotically.

Proof. Assume that $x(t)$ is a positive solution of (1), and $z(t)$ has the case of $(1) ; \omega(t)$ is defined as in (9). Then

$$
\omega^{\prime}(t) \leq-\rho(t) Q(t)+\frac{\rho^{\prime}(t)}{\rho(t)} \omega(t)-\frac{1}{a(t) \rho(t)} \omega^{2}(t) .
$$

Let $B(t)=1 / \rho(t) a(t)$, we have

$$
\rho(t) Q(t) \leq-\omega^{\prime}(t)+\frac{\rho^{\prime}(t)}{\rho(t)} \omega(t)-B(t) \omega^{2}(t) .
$$

We obtain

$$
\begin{aligned}
& \int_{t_{1}}^{t} H(t, s) \rho(s) Q(s) \mathrm{d} s \\
& \leq \int_{t_{1}}^{t} H(t, s)\left[-\omega^{\prime}(s)+\frac{\rho^{\prime}(s)}{\rho(s)} \omega(s)-B(s) \omega^{2}(s)\right] \mathrm{d} s \\
&=H\left(t, t_{1}\right) \omega\left(t_{1}\right) \\
& \quad-\int_{t_{1}}^{t}\left[\left(h(t, s) \sqrt{H(t, s)}-H(t, s) \frac{\rho^{\prime}(s)}{\rho(s)}\right) \omega(s)\right. \\
&= H\left(t, t_{1}\right) \omega\left(t_{1}\right) \\
&-\int_{t_{1}}^{t}\left[\sqrt{H(t, s)} h_{1}(t, s) \omega(s)+H(t, s) B(s) \omega^{2}(s)\right] \mathrm{d} s \\
&= H\left(t, t_{1}\right) \omega\left(t_{1}\right) \\
&+\int_{t_{1}}^{t}\left[\frac{\mathrm{d} s}{4 B(s)} \mathrm{d} s<H\left(t, t_{1}\right) \omega\left(t_{1}\right)+\int_{t_{1}}^{t} \frac{h_{1}^{2}(t, s)}{4 B(s)} \mathrm{d} s .\right. \\
&\left.\quad h_{1}^{2}(t, s) B(s) \omega(s)+\frac{h_{1}(t, s)}{2 \sqrt{B(s)}}\right]^{2} \mathrm{~d} s
\end{aligned}
$$

That is,

$$
\frac{1}{H\left(t, t_{1}\right)} \int_{t_{1}}^{t}\left[H(t, s) \rho(s) Q(s)-\frac{h_{1}^{2}(t, s)}{4 B(s)}\right] \mathrm{d} s \leq \omega\left(t_{1}\right),
$$

which contradicts (19). Assume that (2) holds. We can get $\lim _{t \rightarrow \infty} x(t)=0$. The proof is completed.

\section{Examples}

In this section, we will present two examples to illustrate the main results. 
Example 4. Consider the third-order nonlinear neutral differential equation:

$$
\begin{array}{r}
\left(t\left(x(t)+p_{1} x\left(\frac{t}{2}\right)\right)^{\prime \prime}\right)^{\prime}+\frac{\lambda}{t^{2}} x(t)\left(1+\left(x^{\prime}(t)\right)^{2}\right)=0, \\
\lambda>0, t \geq 1,
\end{array}
$$

where $p_{1} \in[0,1)$, and $K=L=1$. Let $\rho(t)=t$. It follows from Theorem 1 that every solution $x(t)$ of (25) is oscillatory or convergent to zero asymptotically.

Example 5. Consider the third-order nonlinear neutral differential equation:

$$
\begin{aligned}
& \left(\frac{1}{t}\left(t^{1 / 2}\left(x(t)+\frac{1}{2} x\left(t-\frac{1}{2}\right)^{\prime}\right)^{\prime}\right)^{\prime}\right. \\
& \quad+t^{\lambda}\left(\lambda \frac{2-\cos t}{t}+2+\sin t\right) \\
& \quad \times x(t-1)\left(1+x^{2}(t-1)\right)\left(1+\left(x^{\prime}(t)\right)^{2}\right)=0,
\end{aligned}
$$

where $\lambda>0, t \geq 1$. We have

$$
\begin{aligned}
\int_{t_{0}}^{t} q(s) \mathrm{d} s & =\int_{t_{1}}^{t} s^{\lambda}\left(\lambda \frac{2-\cos s}{s}+2+\sin s\right) \mathrm{d} s \\
& \geq \int_{t_{1}}^{t} s^{\lambda}\left(\lambda \frac{2-\cos s}{s}+\sin s\right) \mathrm{d} s \\
& =\int_{t_{1}}^{t} d\left[s^{\lambda}(2-\cos s)\right] \\
& =t^{\lambda}(2-\cos t)-t_{0}^{\lambda}\left(2-\cos t_{0}\right) \\
& \geq t^{\lambda}-K_{0} \longrightarrow \infty(t \longrightarrow \infty) ;
\end{aligned}
$$

we see that $(4)$ and $\left(H_{1}\right)-\left(H_{5}\right)$ hold. Let $H(t, s)=(t-s)^{2}$, $\rho(t)=1$. Then $h_{1}(t, s)=2$. It follows, from Theorem 3 , that the solutions of (26) are oscillatory or convergent to zero asymptotically.

\section{Conflict of Interests}

The authors declare that there is no conflict of interests regarding the publication of this paper.

\section{Acknowledgment}

This research was partially supported by the NNSF of China (11171178).

\section{References}

[1] P. Hartman and A. Wintner, "Linear differential and difference equations with monotone solutions," American Journal of Mathematics, vol. 75, pp. 731-743, 1953.

[2] L. Erbe, "Existence of oscillatory solutions and asymptotic behavior for a class of third order linear differential equations," Pacific Journal of Mathematics, vol. 64, no. 2, pp. 369-385, 1976.
[3] L. H. Erbe, Q. Kong, and B. G. Zhang, Oscillation Theory for Functional-Differential Equations, vol. 190 of Monographs and Textbooks in Pure and Applied Mathematics, Marcel Dekker, New York, NY, USA, 1995.

[4] R. P. Agarwal, S. R. Grace, and D. O’Regan, "Oscillation criteria for certain $n$th order differential equations with deviating arguments," Journal of Mathematical Analysis and Applications, vol. 262, no. 2, pp. 601-622, 2001.

[5] J. Džurina, "Asymptotic properties of the third order delay differential equations," Nonlinear Analysis. Theory, Methods \& Applications, vol. 26, no. 1, pp. 33-39, 1996.

[6] T. Candan and R. S. Dahiya, "Functional differential equations of third order," in Proceedings of the Conference on Differential Equations and Applications in Mathematical Biology, vol. 12, pp. 47-56, 2005.

[7] T. Li, C. Zhang, and G. Xing, "Oscillation of third-order neutral delay differential equations," Abstract and Applied Analysis, vol. 2012, Article ID 569201, 11 pages, 2012.

[8] Z.-Y. Han, "Oscillations of a class of third order nonlinear neutral functional differential equations," Journal of East China Normal University, no. 1, pp. 113-120, 2012.

[9] B. Baculíková and J. Džurina, "Oscillation of third-order functional differential equations," Electronic Journal of Qualitative Theory of Differential Equations, vol. 43, pp. 1-10, 2010.

[10] M. F. Aktaş, A. Tiryaki, and A. Zafer, "Oscillation criteria for third-order nonlinear functional differential equations," Applied Mathematics Letters, vol. 23, no. 7, pp. 756-762, 2010.

[11] S. R. Grace, R. P. Agarwal, R. Pavani, and E. Thandapani, "On the oscillation of certain third order nonlinear functional differential equations," Applied Mathematics and Computation, vol. 202, no. 1, pp. 102-112, 2008.

[12] R. P. Agarwal, S. R. Grace, and D. O'Regan, "The oscillation of certain higher-order functional differential equations," Mathematical and Computer Modelling, vol. 37, no. 7-8, pp. 705-728, 2003.

[13] S. H. Saker, "Oscillation criteria of third-order nonlinear delay differential equations," Mathematica Slovaca, vol. 56, no. 4, pp. 433-450, 2006.

[14] S. H. Saker and J. Džurina, "On the oscillation of certain class of third-order nonlinear delay differential equations," Mathematica Bohemica, vol. 135, no. 3, pp. 225-237, 2010.

[15] R. P. Agarwal, M. F. Aktas, and A. Tiryaki, "On oscillation criteria for third order nonlinear delay differential equations," Archivum Mathematicum, vol. 45, no. 1, pp. 1-18, 2009.

[16] T. S. Hassan, "Oscillation of third order nonlinear delay dynamic equations on time scales," Mathematical and Computer Modelling, vol. 49, no. 7-8, pp. 1573-1586, 2009.

[17] T. Li, Z. Han, S. Sun, and Y. Zhao, "Oscillation results for third order nonlinear delay dynamic equations on time scales," Bulletin of the Malaysian Mathematical Sciences Society, vol. 34, no. 3, pp. 639-648, 2011.

[18] E. Thandapani and T. Li, "On the oscillation of thirdorder quasi-linear neutral functional differential equations," Archivum Mathematicum, vol. 47, no. 3, pp. 181-199, 2011.

[19] R. P. Agarwal, B. Baculikova, J. Džurina, and T. Li, “Oscillation of third-order nonlinear functional differential equations with mixed arguments," Acta Mathematica Hungarica, vol. 134, no. 1-2, pp. 54-67, 2012. 


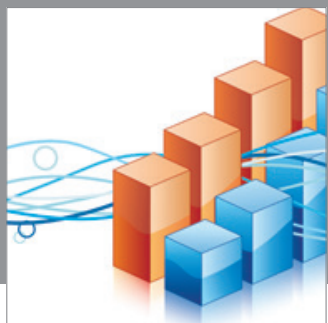

Advances in

Operations Research

mansans

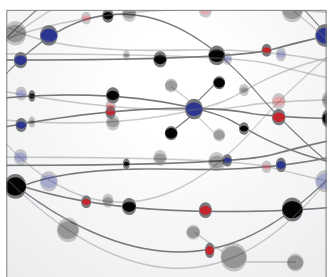

The Scientific World Journal
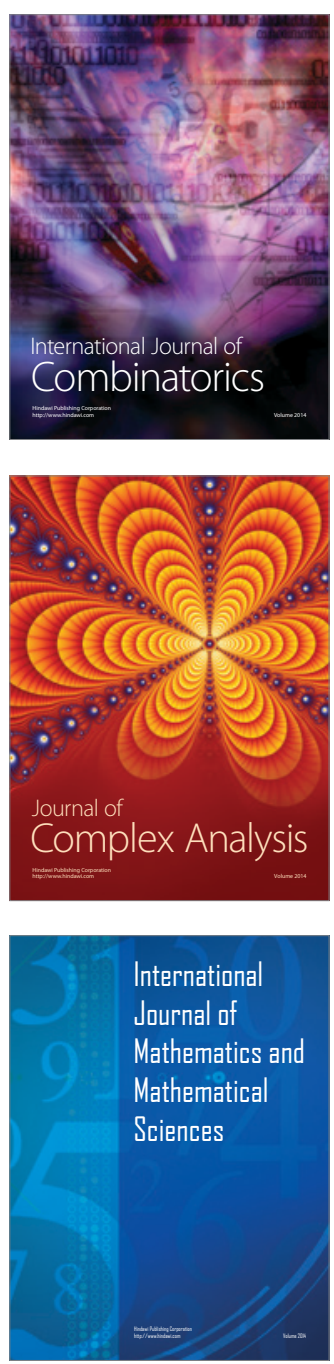
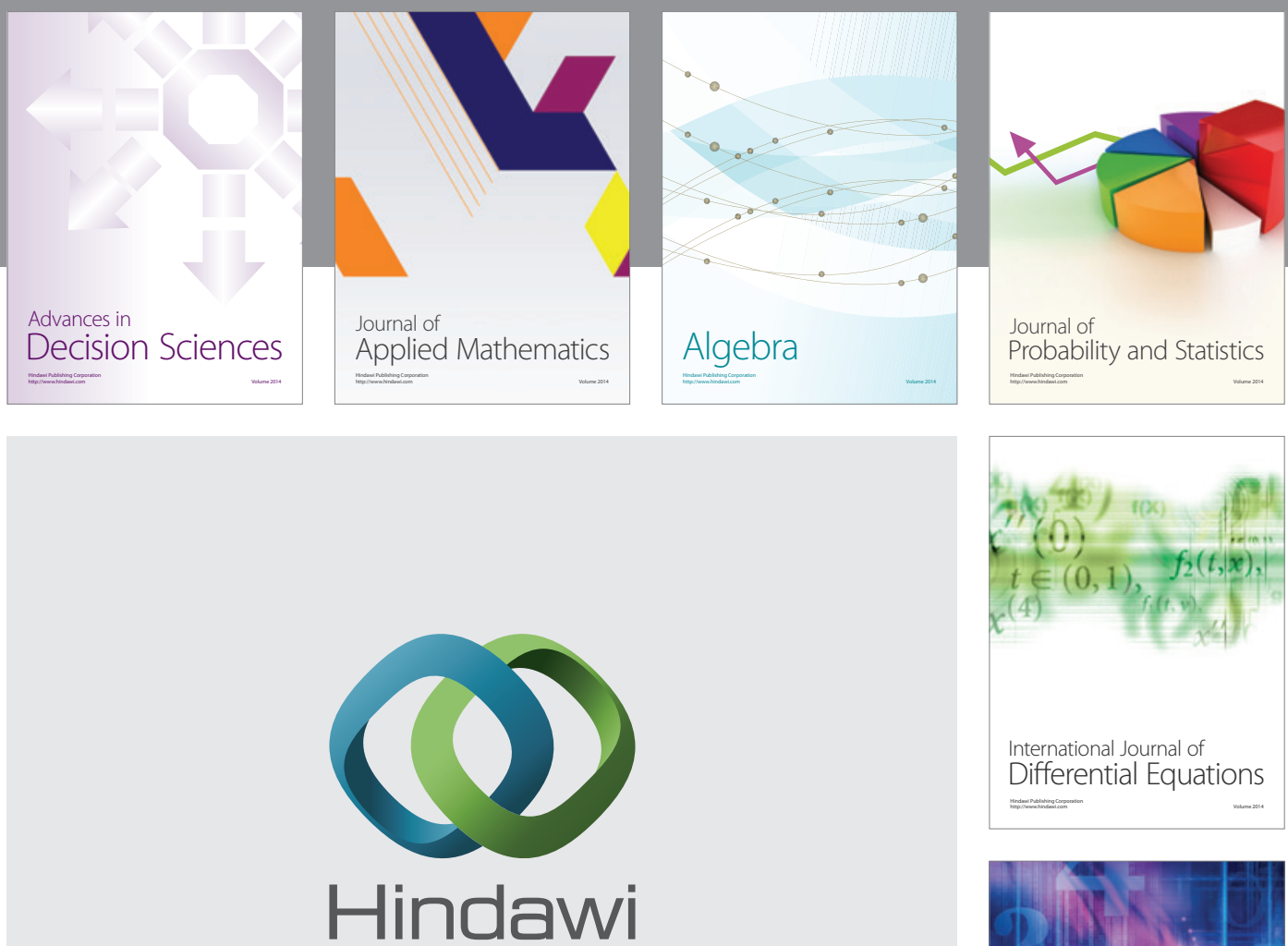

Submit your manuscripts at http://www.hindawi.com
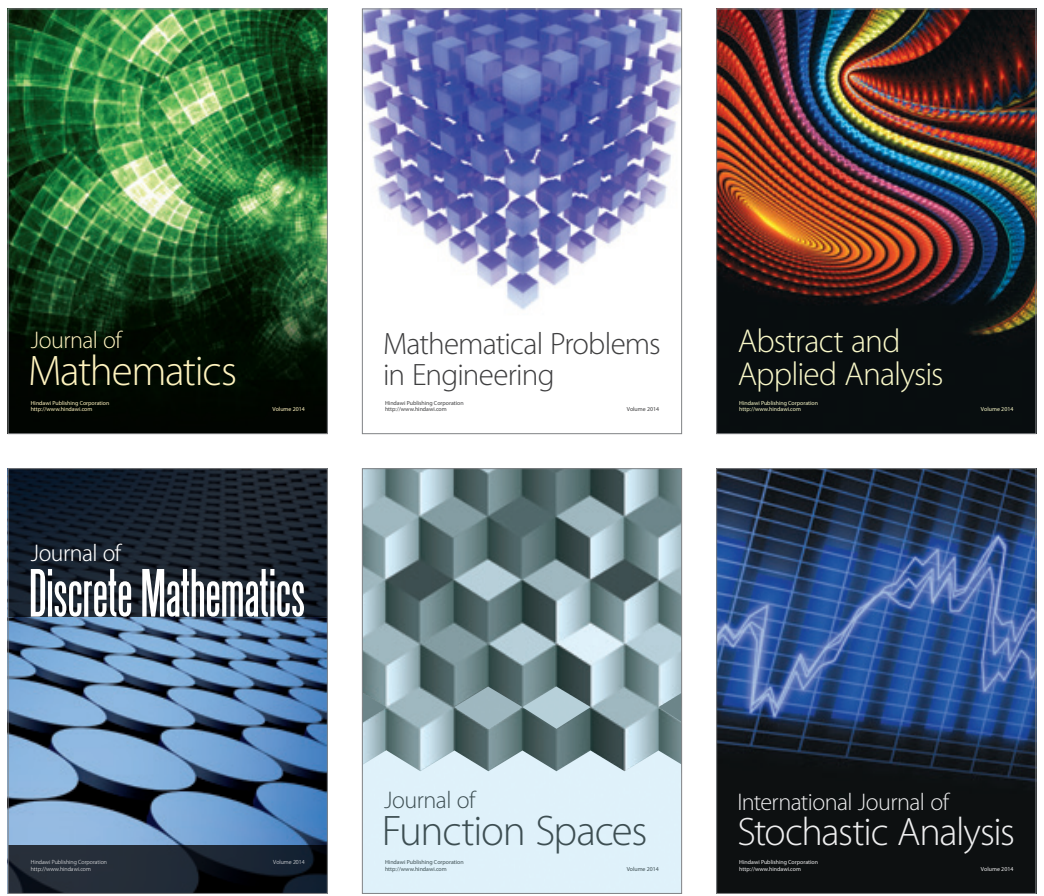

Journal of

Function Spaces

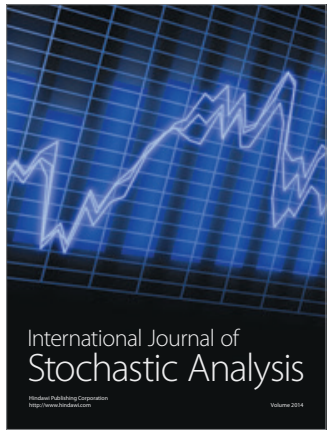

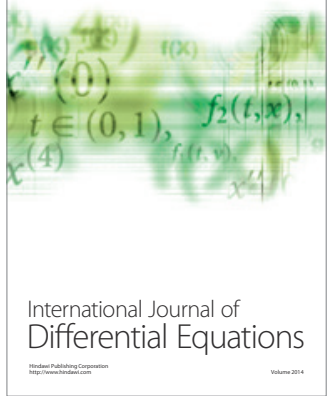
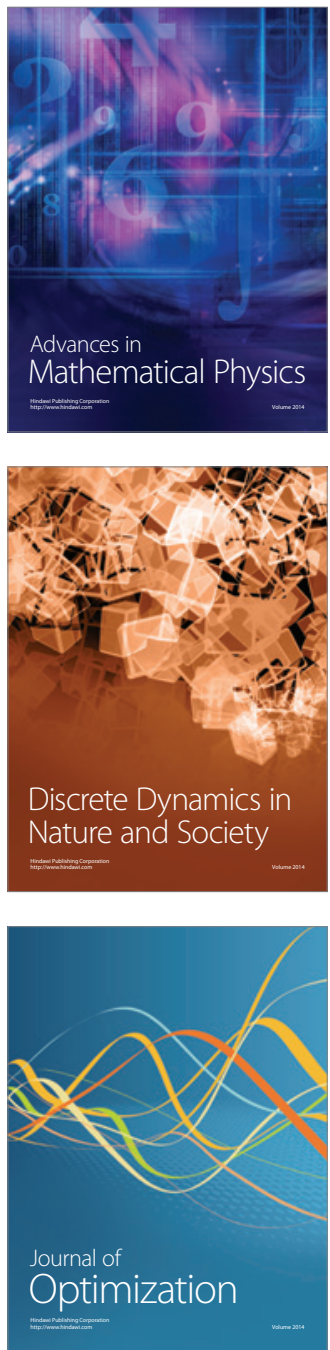